\title{
A HISTÓRIA DAS HAVAIANAS E A CONSTRUÇÃO DE UM MITO: O JEITINHO BRASILEIRO QUE TODO MUNDO USA
}




\section{A HISTÓRIA DE HAVAIANAS E A CONSTRUÇÃO DE UM MITO: O JEITINHO BRASILEIRO QUE "TODO MUNDO USA"}

Resumo:

Este trabalho se propõe a responder a seguinte pergunta: como se dá a construção de um mito no slogan "Havaianas: Todo mundo usa"? Parte-se da hipótese de que haja um mito envolvendo o "todo mundo", que aparentemente é o "todo mundo brasileiro". A última etapa será a de testar os conceitos de construção de mito e "jeitinho brasileiro" no decorrer da história da Havaianas e, por fim, responder como se dá a construção de um mito em volta do "todo mundo" de Havaianas.

Palavras chave: Construção mítica; jeitinho brasileiro; Havaianas

\section{HAVAIANAS HISTORY AND A CONSTRUCTION OF A MYTH: THE BRA- ZILIAN WAY THAT "EVERYONE USES"}

Abstract:

This paper proposes to answer this question: how happens the construction of a myth at the slogan "Havaianas: Everyone uses"? It starts with a hypothesis that there are a myth involving the "everyone", who apparently is the "everyone Brazilian". The last part will be testing the concepts of construction of a myth and "Brazilian way" during the history of Havaianas and, lastly, answer how happens the construction of a myth around the "everyone uses" of the Havaianas.

Keywords: Mythical construction; Brazilian way; Havaianas

\section{LA HISTORIA DE HAVAIANAS Y LA CONSTRUCCIÓN DE UN MITO:LA MANERA BRASILEÑA QUE "TODO MUNDO USA"}

\section{Resumen:}

Este trabajo se propone a contestar la siguiente pregunta: como se da la construcción de un mito en el slogan "Havaianas: todo mundo usa"? Partéese de la hipótesis de que haya un mito envolviendo el "todo mundo", que aparentemente es lo "todo mundo brasileño". La ultima etapa será la de testear los conceptos de construcción de mito y "manera brasileña" en el pasar de la historia de Havaianas y, por fin, contestar como ocurre la construcción de un mito en vuelta del "todo mundo" de Havaianas.

Palabras Clave: Construcción mítica; manera brasileña; Havaianas 


\section{INTRODUÇÃO}

Este trabalho é um recorte da monografia "Processos Ensaísticos em uma Campanha Publicitária: Personagens e o 'Todo Mundo' em Havaianas”, apresentada ao Curso de Comunicação Social, Habilitação Publicidade e Propaganda, da Universidade Federal de Santa Maria, no ano de 2010. O artigo tem como tema a marca Havaianas e é delimitado pela seguinte questão: como se dá a construção de um mito no slogan da marca Havaianas, "Havaianas: Todo mundo usa"?

Os estudos em publicidade nos mostram desde muito cedo que, para qualquer campanha e/ou anúncio obter êxito, o público-alvo deve ser delimitado e especificado. Porém, na contramão da teoria, a marca Havaianas possui um slogan que generaliza o seu público e que parece funcionar.

A sandália teve vários slogans durante a sua história, "Havaianas: As Legítimas", "Não deformam, não soltam as tiras e não têm cheiro" e, finalmente, "Havaianas: Todo mundo usa". Os slogans da marca retratam a passagem da sandália de um contexto mais tangível, quando aqueles tentavam diferenciá-la das imitações e afirmá-la como um produto de qualidade ("legítimas", "não deformam, não soltam as tiras e não têm cheiro") para outro totalmente intangível, acrescentando valor de marca (aquela que "todo mundo usa", ricos e pobres, anônimos e famosos).

Apesar de o público de Havaianas ${ }^{1}$ ser composto pelos mais diversos segmentos da sociedade, a intenção parece ser a de que todos estes se vejam representados de alguma forma no slogan e nas campanhas da marca. É isso que, em uma primeira visada, facilita a aproximação da sandália com o seu público bastante eclético.

Para confirmarmos o possível mito envolvendo o "todo mundo" é inevitável buscarmos conceitos do "jeitinho brasileiro", pois, o "todo mundo", aparentemente, se refere ao "todo mundo brasileiro". Trabalhando com as origens do nosso jeito de ser, procuraremos verificar esta hipótese.

Para isso, iremos analisar a história dos slogans da marca e também a Campanha de Verão 2009, cuja temática é "Havaianas: o verão começou". Esta campanha possui três VT's comerciais de 30 segundos que se intitulam: "Havaianas: jeito de falar", "Havaianas: favorzinho" e "Havaianas: democracia". Como já ocorre há muitos anos, os VT’s são coroados com o slogan, "Havaianas: Todo mundo usa".

Para formular a nossa hipótese de construção de mito em Havaianas partimos de alguns questionamentos. Por exemplo, por que imaginamos que a Havaianas, com o "todo mundo", esteja criando ou já tenha criado um mito; precisamos saber como se constrói um mito; se este modelo de construção

1 Público de Havaianas está aqui representando o público consumidor ou prospectado das sandálias Havaianas. 
se aplica à marca; se o "todo mundo" é demarcado pela presença do homem cordial, do "jeitinho brasileiro", e se existe ou não o mito de "todo mundo" em Havaianas.

Assim, dividimos este artigo em três passos: A construção de um mito, Havaianas: começo, meio e recomeço e Considerações Finais. No primeiro passo, iremos abordar os conceitos envolvidos na construção de um mito e do "jeitinho brasileiro", para isso, buscamos os autores: Barthes (1999), Petermann (2007), Holanda (1995), DaMatta (2009a e 2009b) e Peruzzolo (2006). No segundo passo, apresentaremos a história das sandálias Havaianas segundo Breunig (2006) e Serralvo (2006). No terceiro passo, partiremos para a análise da construção mítica em "Havaianas: Todo mundo usa" a partir dos slogans da marca e verificaremos se os comerciais da Campanha de Verão 2009, "Havaianas o Verão Começou" atuam como reforço para esta teoria.

\section{A CONSTRUÇÃO DO MITO}

Um mito se constrói através de uma linguagem e, segundo Barthes (1999), esta linguagem é mais um fragmento da grande semiologia (ciência que se ocupa das formas, estudando as significações independentemente dos conteúdos) que Saussure nos apresentou há muito tempo atrás.

Para ele, a semiologia trata da relação de dois termos: o significante, que, compartilhando das idéias de Saussure, carrega a imagem acústica, e o significado, o conceito segundo. Conforme afirma Barthes (1999), se pesquisarmos os sistemas semiológicos encontraremos três termos diferentes desta relação significante e significado. Isso por que o significante ao expressar o significado origina o signo, pensando desta forma a relação entre a imagem acústica e o conceito nos dá um terceiro elemento, o signo.

Ocorre que no mito esta mesma relação tridimensional se apresenta de forma mais complexa. Para o autor, o mito vai além e se transforma em um sistema particular e, também, mais complexo. O mito utiliza o significante, o significado e o signo para construir e se instalar em um segundo sistema, ou seja, aquilo que primeiramente é signo passa a ser significante. Pensando desta forma, a relação que existia entre imagem acústica e conceito, o signo, é deixada de lado e ele adota a categoria de significante para, juntamente com um novo significado, formar um novo signo. Conforme Petermann (2007), é através destas relações significante-significado que um mito é construído: são os diferentes significantes que contribuem para a formação de uma imagem mítica.

Para facilitarmos o entendimento vamos fazer um passo a passo da construção de um mito:

$1^{\circ}$ Unimos um significante a um significado; 
$2^{\circ}$ Como resultado teremos um signo;

$3^{\circ} \mathrm{O}$ signo formado passará a ser o nosso significante;

$4^{\circ}$ Este novo significante se juntará com um novo significado;

$5^{\circ}$ Um novo signo será formado, o de mito.

Do primeiro ao segundo passo estamos falando da linguagem que representa todas as coisas no mundo. Por exemplo, um pano branco adicionado ao tremular e empunhado por alguém, indica um sinal de paz, isso está no campo da linguagem. A partir deste ponto começa a se pensar na formação do mito. Do segundo ao quinto passo

o signo tomará o lugar de significante, se juntará com um novo significado e formará um novo signo, isto é mitificação.

A partir desta proposição, o autor, sugere novas nomenclaturas para a linguagem e o mito. A linguagem passa a ser referida como linguagem objeto, já que, o mito se apropria dela para formular um novo sistema e o mito passa a ser uma metaliguagem, pois, produz uma segunda linguagem para falar da primeira.

Podemos pensar que este sistema de metalinguagem, proposto por Barthes, serve-nos para entender como se formou o mito do "jeitinho brasileiro", pela adição de inúmeros valores, segundo Holanda (1995). Sendo assim, podemos imaginar a construção de um mito, já que, fomos agregando valores e formas à nossa identidade ao longo do tempo.

Ao pensarmos o "jeitinho brasileiro" através dos cinco passos de Barthes (1999), podemos construir o seguinte sistema:

Tabela 1: Construção do Jeitinho Brasileiro

\begin{tabular}{|l|l|}
\hline Homem & Família \\
Brasileiro & \\
\hline
\end{tabular}

\begin{tabular}{|l|l|}
\hline Cordialidade & Coletividade \\
\hline Grandes Famílias & Emoção \\
\hline Afabilidade & Malandro \\
\hline
\end{tabular}

"Jeitinho Brasileiro"

Assim, existia o homem brasileiro, lá dos primeiros tempos, que quando foi colonizado, segundo Holanda (1995), adotou alguns valores do povo que chegou. Por isso, até hoje, a nossa cultura é intensamente patriarcal. Dentro dos grupos patriarcais, a família sempre foi o que mais teve força. Segundo o autor, é por esse motivo que o brasileiro utiliza as relações domésticas como modelo para as relações na sua vida social.

Agora, se o tratamento para com os membros da nossa família é a base 
que usamos para construir as nossas relações na sociedade, então, como diz Holanda (1995), nós não podemos contribuir de outra forma com a civilização que não seja com a cordialidade. Aí temos nosso primeiro signo. Como sabemos, e o autor reforça, o cuidado no trato com os outros, a hospitalidade, a simpatia e a generosidade com que tratamos os estrangeiros em nosso país fazem parte da nossa cultura e do nosso "jeitinho". Para o autor, são também estes os valores que definem o caráter brasileiro, fazendo do homem cordial um indivíduo espontâneo, natural e vivo.

A este homem brasileiro, da família e da cordialidade se une mais um significado, o de coletividade. Como já disse Peruzzolo (2006), temos a necessidade de nos relacionarmos com o mundo, pois ninguém consegue viver sozinho. O fato de que o homem precisa viver em relações, para Holanda (1995), está relacionado com um medo de nos acharmos sozinhos, de contarmos apenas conosco. É por isso que buscamos tanto a vida em sociedade.

Porém, ao mesmo tempo em que buscamos a sociedade e precisamos dela, ela nos sufoca. Como nos diz o antropólogo DaMatta (2009b)2, criou-se por aqui uma espécie de regra que nos impede de ficarmos sozinhos. Podemos reparar que quando passamos uma tarde inteira no quarto estudando, muitas são as vezes que somos chamados para constituir um grupo. Neste momento, chegamos ao nosso segundo signo, as grandes famílias. Não raro nos deparamos com uma empresa se intitulando família, isso por que a sociedade brasileira representa a grande família.

Agora mais um significado é acrescentado ao brasileiro, a emoção. Somos um povo que possui calor humano, que se abraça e se beija. Mas não é só nesses gestos que traduzimos a emoção. Por exemplo, no dia-a-dia utilizamos diversas vezes a terminação "inho", os amigos do seu filho são "amiguinhos", um cachorro bonito é "cachorrinho", você convida uma amiga para tomar um "sorvetinho", isto porque o emprego do sufixo diminutivo aproxima pessoas e pessoas, pessoas e objetos, pessoas e animais, ou seja, é uma forma de aproximar a relação do coração, conforme Holanda (1995).

Holanda (1995, p.147), afirma que somos um povo cordial e no cordial existe "um fundo emotivo extremamente rico e transbordante", e somos isto mesmo, uma emoção que transborda ao ver a seleção jogar, encontrar um amigo, ver a família, ver um estrangeiro falando bem do nosso país. Mas também, é uma emoção que transborda nos cumprimentos, no costume que temos de abraçar e beijar quando nos encontramos, que nos é tão comum e tão incomum aos olhos de outras nações.

Assim, construímos o nosso terceiro signo, a afabilidade do povo brasileiro. Somos o homem brasileiro, da família, da cordialidade, da coletividade, das grandes famílias, da emoção, da afabilidade e agora, quando mais um significado se une, do malandro. O malandro brasileiro, é aquele que sempre dá

2Referência disponível em: <http://www.chmkt.com.br/2009/11/entendendo-nosso-jeito-brasileiro-dee_24.html>, postado em 2009. 
um jeitinho em qualquer situação. Por isso, segundo DaMatta (2009a) ${ }^{3}$, o jeito é um modo de se resolver um problema, de se harmonizar os interesses opostos, de equilibrar as diferenças, e, portanto, o malandro seria o expert em dar sempre um "jeitinho" e, assim, sobreviver mesmo nas situações mais difíceis.

Para o autor, a forma mais simples de explicar quem é o malandro, é representálo como aquele que sempre fica no meio do caminho, junta a lei, impessoal e impossível, com a amizade e a relação pessoal, que diz que cada homem deve ser tratado de modo especial. E que faz da malandragem um modo de ser possível.

Agora, finalmente, chegamos ao "jeitinho brasileiro". Como vimos, ele é construído através da nossa história e daqui a séculos mais signos irão surgir, pois, estamos sempre em construção. Isso nos faz imaginar que o sistema mítico que foi apresentado por Barthes (1999), pode ser associado ao conceito de semiose infinita proposto por Pierce, segundo Peruzzolo (2004). Isso por que o signo que se torna significante e se une a um novo significado, forma um novo signo, que poderia tornar-se significante, unir-se a outro significado e, assim, infinitamente. Remetemos à semiose infinita de Pierce não pelas categorias ou pelas formas dos elementos, mas, pelo modo como o processo se dá: na forma de uma cadeia sucessiva e interminável de novas proposições de sentidos.

Prestando atenção a um último detalhe, veremos que até o jeito brasileiro, se aproxima do coração, é o "jeitinho". Utiliza-se a sufixação diminutiva "inho" para designar o nosso modo de ser, para tornar mais agradável um modo de conduta que muitas vezes não o é. Desta forma, a malandragem, a esperteza, a trapaça, a fraude, são minimizadas e tratadas apenas como um modo de conduta, desculpadas pela necessidade de improviso, de adequação e até de sobrevivência.

\section{HAVAIANAS: COMEÇO, MEIO E RECOMEÇO}

Na década de 60, segundo Breunig (2006), o Brasil era tipicamente agrário e a população não tinha grande poder aquisitivo, assim, os consumidores buscavam produtos com preços baixos e que fossem de qualidade. Foi nesta ocasião que a Havaianas criou uma sandália de borracha, que é um produto 100\% natural. Para Breunig (2006), o ano de 1962 é histórico, pois surge a primeira Havaianas, reproduzindo o solado de arroz da sandália japonesa Zori, desde então, sua marca registrada.

3 Referência disponível em: <http://umaspalavrasmila.blogspot.com/2009/05/malandrageme-o-jeitinhobrasileiro.html>, postado em 2009. 


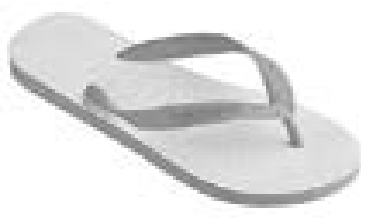

Figura 1: Primeiro modelo das Havaianas

(Fonte: http://www.radiocesumar.com.br/megafone/agencia/data/upimages/havaiana_azul.jpg)

No ano de 1988, conforme Serralvo (2006), a Havaianas teve uma grande queda nas vendas, de 80 para 65 milhões de pares vendidos, isso se explica de várias formas. A empresa ficou 31 anos, de 1962 até 1993, sem modificar o produto e enquanto isso, novos produtos surgiram para concorrer, como por exemplo, os chinelos Rider da Grendene.

Esta era a hora de se reposicionar no mercado e a base da mudança estava no público-alvo. Conforme Breunig (2006), a empresa saiu em busca das classes B e C. A marca que até então era comercializada em supermercados, e lojas populares, dentro de sacos plásticos amarrados com barbante, deixou definitivamente de ter um tratamento de commodity e de ser um "chinelo de pobre".

O primeiro grande passo surge no ano de 1993 com a linha Havaianas Top. A idéia para a coleção parte do público, que durante as décadas anteriores virava a sandália com o solado para cima dando a idéia de que a sandália era monocromática.

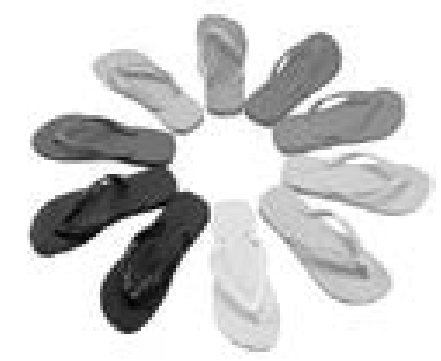

Figura 2: Parte da linha Havaianas Top

(Fonte: http://password.blog.br/cotrimus/wp-content/uploads/2009/09/havaianas-300x300.jpg)

Para Breunig (2006), o lançamento da sandália foi inovador, o foco passou para o varejo calçadista formador de opinião, a classe A. Nos comerciais de televisão, conforme informa o site da empresa, pessoas famosas mostravam seus pés, coroando o novo slogan, "Havaianas: Todo mundo usa". Para as novas linhas, apostou-se em design, novas embalagens, displays de apresentação, novas cores e tonalidades. As Havaianas também investiram em Assessoria de Imprensa, Relações Públicas e Promoção de Eventos, conforme Breunig (2006). Concomitantemente, foi criado o website da empresa para três países. Hoje, já são 19 lugares pelo mundo. 
Em 1998, a Havaianas lançou um modelo em comemoração à Copa do Mundo. O modelo apresentava uma pequena bandeira do Brasil na tira, o que fez com que os brasileiros se identificassem e que aqueles residentes no exterior exibissem com orgulho suas sandálias. Como o próprio site da empresa ressalta "a copa de 98 não veio para o Brasil, mas as Havaianas serão para sempre".

Para marcar oficialmente as Havaianas no exterior, o lançamento das sandálias foi em Paris, na Galeries Lafayette, em um Festival da América Latina, afirma Breunig (2006). Neste evento, várias empresas da América Latina se fizeram presentes e, segundo Serralvo (2006), a medida adotada para se diferenciar das outras marcas foi construir no espaço das Havaianas uma minifábrica para que as pessoas pudessem customizar suas sandálias, pagando um preço mais alto pelo produto. A idéia foi um sucesso e Havaianas já entrou no mercado internacional como um artigo de luxo. Breunig (2006) destaca que outra estratégia encontrada para agregar valor foi a forma de venda. As sandálias não foram vendidas em supermercados, como é feito no Brasil, além disso, seus distribuidores sempre tiveram acesso a grandes eventos, como Grammy e Oscar, e foram promovidas ações em lojas como a Au Printemps em Paris.

\section{CONSIDERAÇÕES}

A mudança de postura da marca Havaianas e as mudanças que ocorreram conjuntamente nos seus slogans, nos trouxe o pensamento de que a Havaianas pudesse estar construindo um mito em torno do "todo mundo usa". Para saber se isso realmente ocorre, optamos por considerar os slogans a partir do modelo de Barthes que apresentamos anteriormente. Acreditamos que os slogans representam a trajetória da marca e, portanto, também, a construção mítica.

Anteriormente, formulamos um passo a passo para os conceitos de Barthes (1999). O primeiro passo, segundo o autor, consiste em adicionar um significante a um significado. No caso Havaianas, o nosso significante é uma sandália (chinelo), a este significante a marca agrupou, em um primeiro momento os significados contidos no slogan, "As Legítimas", que surgiu como uma forma de alertar o consumidor de que aquela era a original, era a primeira. Com o surgimento e sucesso de Havaianas, muitas cópias surgiam e a marca teve de fazer algo que a colocasse novamente em destaque. Assim, utilizou-se da mesma arma que lhe estava sendo apontada: se imitações surgiam, ela postou-se como a original.

Neste momento, Havaianas já não é mais uma simples sandália, é uma sandália original, pois, é a primeira, a precursora e aqui temos a primeira formação mítica. Surge então um novo slogan e um novo significado que se une ao mito primeiro, que então assume a função de significante: "Não deformam, não soltam as tiras e não têm cheiro". Aqui se aplica uma descrição do pro- 
duto, dizendo por que ela é melhor, porque ela, diferente das imitações, não deforma, não solta as tiras e não tem cheiro. Trata-se de uma forma totalmente tangível de se afirmar o produto. Por isso, dizemos que estes dois slogans têm uma forma mais tangível de se relacionar com o público. Apesar de "As Legítimas" possuir certa subjetividade, criar um valor de legitimidade no imaginário do consumidor, ela está mais voltada para a diferenciação das imitações que aparecem e, por isso, precisa se firmar como original. Já o segundo conceito, diz respeito somente à descrição do produto, cria um valor, que é totalmente tangível.

Neste momento, a Havaianas é legítima, que não deforma, não solta as tiras e não tem cheiro. Em 1993, segundo Breunig (2006) a marca passa por uma reformulação e decide se reinventar. Na década de 1990, os conceitos de marca ganhavam espaço e não se podia pensar em somente descrever o produto.

Com isso, Havaianas muda completamente sua postura, vai buscar outros públicos, além daqueles que já tinha e coloca em todas as campanhas publicitárias, celebridades. Aqui, já falamos em agregar valor e o valor em questão se traduz com "Havaianas: Todo mundo usa". Assim, o mito segundo, formado com o significado de "não deformam, não soltam as tiras e não têm cheiro" torna-se o significante do mito terceiro, formado com o acréscimo do significado "Todo mundo usa".

Agora, Havaianas é a marca que possui na sua formação o significante "sandália" que se uniu ao significado "legítimas" e formou, "Havaianas: As Legítimas". Depois, com o significante "Havaianas: As legítimas" ela se uniu ao significado "Não deforma, não solta as tiras e não tem cheiro" e se tornou "Havaianas: as legítimas, que não deformam, não soltam as tiras e não têm cheiro". A partir disso, o significante passa a ser "Havaianas: as legítimas, que não deformam, não soltam as tiras e não têm cheiro" e a todos estes valores se agrega o "todo mundo usa", então, Havaianas é "as legítimas, que não deformam, não soltam as tiras, não têm cheiro e que todo mundo usa". Sendo assim, Havaianas não tentou criar um mito, ela conseguiu. Assim, constrói-se um mito na marca Havaianas que envolve o "todo mundo" e que conserva valores tangíveis e intangíveis do produto e da marca.

Constando a presença de um mito, iremos analisar os três vt's comercias da Campanha de Verão 2009 que se intitula "Havaianas: o verão começou", para então, podermos saber se o mito do "jeitinho brasileiro" também se apresenta nos comerciais da marca, reforçando a nossa hipótese.

Para melhor entendimento da campanha faremos agora um breve resumo dos três comerciais. No primeiro comercial, "Havaianas: jeito de falar", Fernanda Tavares e Murilo Rosa estão na praia quando ela decide ir para o mar. Uma bola bate no pé de Murilo e um rapaz vem buscá-la. Ele vê as Havaianas de Fernanda e elogia. O rapaz então elogia Fernanda e Murilo pede mais respeito com sua esposa. O rapaz faz o mesmo elogio só que com um vocabulário mais 
rebuscado e Murilo sai correndo atrás dele. No segundo comercial, "Havaianas: favorzinho", Fernanda está sentada na praia quando um rapaz pede a ela para cuidar suas Havaianas. Ela responde que sim e ele se senta ao seu lado. Contrariada ela pergunta: "você não disse que era pra eu olhar as suas Havaianas?" E ele faz uma piada "pode olhar". Fernanda avisa que seu marido está ali e o rapaz responde que ela é mais bonita. No terceiro comercial, "Havaianas: democracia", Fernanda compra um sorvete e vai ao encontro de Murilo. O sorveteiro faz um comparação entre ele (feio, pobre e de Havaianas) e Murilo (bonito, rico e de Havaianas).

Inicialmente, percebemos que os três comerciais se passam na praia. Esta já é uma forma de inserir o brasileiro, pois, como o país possui uma grande extensão litorânea, o brasileiro logo se identifica com esta representação. A praia é um lugar em que muitas pessoas aproveitam para fazer novas amizades e paquerar, duas características do nosso povo.

Se pensarmos a praia por outro viés, classificando-a no tempo, verão de 2009, encontraremos o estereótipo do Brasil, verão e praia. Esse já seria um argumento para reforçar o mito e que ele possui relação com o brasileiro. Porém, podemos ir ainda mais adiante, o grande estereótipo da vida do brasileiro é a chegada de final de ano e a sua virada, por que esta é a época de verão, praia e férias. Por isso, são os meses mais esperados e é, neste momento, que surge a nova coleção Havaianas, colorindo o verão, a praia e as suas férias. Publicitariamente, é uma grande estratégia, pois a companheira de praia, verão e férias dos brasileiros é a sandália.

Os VT's comercias possuem três personagens nos dois primeiros VT's da campanha (Murilo Rosa, Fernanda Tavares e um indivíduo comum, que chamaremos de terceiro elemento) e quatro no último. Fernanda e Murilo representam dois papéis: a celebridade, com todo o glamour que isto envolve, representam o que todo indivíduo deseja ser: bonito, rico, famoso, bem casado. Como dizem Vestgaard e Schroder (1988), "não existiria fascínio se a inveja social dos seres humanos não fosse uma emoção comum e generalizada", ou seja, todos temos desejos de ser o outro, aquele que projetamos como ideal de vida.

Porém, mesmo representando celebridades, o casal também se apresenta como a si mesmos, e, justamente, por isso, não deixam de ser brasileiros, em primeira instância. Veremos agora como o "jeitinho brasileiro" se manifesta neles, mesmo não sendo caracterizados ou estereotipados como tal.

No primeiro VT, a forma como Fernanda trata Murilo pode ser considerada um aspecto brasileiro, pois, em muitos países os casais não se beijam em locais públicos, diferentemente, daqui. Seguindo o comercial, apesar de Murilo não dar grande atenção ao terceiro elemento, ele também não ignora, continua a conversa dando certa atenção. Este aspecto foi citado anteriormente para falar da quase obrigação a que somos submetidos em relação a ter que dialogar quando alguém nos interpela, seja na rua, na praia ou na parada de ônibus (DAMATTA 2009b). 
No segundo VT, Fernanda se dispõem a cuidar das sandálias do desconhecido, o que é muito comum em praias brasileiras. Esta disponibilidade, é uma característica do nosso povo.

Por fim, no último VT, Fernanda se apresenta bem caracterizada. É muito simpática e delicada com o sorveteiro, chama-o pelo nome, joga beijo. Estas são atitudes típicas do jeitinho brasileiro, segundo Holanda (1995), simpatia, afetuosidade, carinho, são formas que o brasileiro encontra de fazer com que as pessoas fiquem mais perto do coração, talvez, pelo possível medo de se acharem sozinhas, como já disse o autor.

A partir de agora falaremos dos outros personagens que aparecem nos comerciais, e que se relacionam na trama narrativa com o casal de celebridades. A primeira grande característica brasileira nestes personagens é a forma como se apresentam. Apesar de serem três atores diferentes que se apresentam nos comerciais como o terceiro elemento, como designamos, este aspecto nos passa quase despercebido. É, justamente, aqui que entra o estereótipo do brasileiro: os três se apresentam como biótipos do brasileiro: magros, de pele clara, cabelo escuro e barbudos. Por quantos tipos como esses passamos todos os dias nas ruas?

O terceiro elemento é aquele que surge para trazer o humor dos dois primeiros VT's. É o “jeitinho brasileiro” de com tudo fazer graça, de sempre tentar levar alguma vantagem, que caracteriza esse dois personagens. O humor é a forma positiva de inserir o consumidor no comercial, já que, tendo duas celebridades no comercial as pessoas se identificariam com elas. Porém, a marca quer dizer que todo mundo usa Havaianas, então, o público deseja ser como os famosos, mas, se identifica também com o anônimo que é cômico. No último VT, o terceiro elemento não utiliza o humor, mas, se coloca em uma posição de inferioridade. Sabemos que o brasileiro sempre se compadece dos mais fracos, ou seja, dizer que é "feio" e "pobre" é uma estratégia de aproximação com o público. Além disso, esta mesma passagem serve para dizer: "eu não sou o Murilo Rosa, mas, também tenho Havaianas". A empresa quer convencer o consumidor de que todos, sem exceção, podem ter uma Havaianas, e que este produto de alguma forma pode representar certo tipo de ascensão social, até o nível das celebridades.

Além de todas estas características, podemos apresentar outras mais específicas. Por exemplo, no primeiro VT, o terceiro elemento apresenta, logo na sua entrada, um aspecto bem brasileiro do diálogo, segundo DaMatta (2009b). Ele inicia o diálogo com Murilo, sem grandes cerimônias, sem saber se o outro gostaria de conversar, sem nem se apresentar. Seguindo o comercial, temos a presença de uma bola de futebol, nada mais brasileiro do que isso: a bola fica entre os dois atores durante todo o diálogo do anúncio de Havaianas.

A forma como a Havaianas se postou após 1993, também corrobora o argumento para a formação de um mito. As sandálias estão em todos os lugares, estão em diversos países, estão na Au Printemps, no Grammy, no Oscar, no 
São Paulo Fashion Week e nos casamentos de famosos. Na medida em que as sandálias são o presente que os noivos dão aos seus convidados, isto reafirma o mito de que "todo mundo usa" e de que havaianas é tão bonita e tradicional que serve como uma lembrança de casamento, juntamente, com a maior lembrança de casamento que é o "bem casado". Quem sabe daqui a alguns anos esta atitude seja tão tradicional que presentear apenas com o "bem casado" não irá mais significar sucesso no casamento, será preciso dar também uma Havaianas customizada do casal. Assim, a sandália fará definitivamente parte da grande cultura que envolve os casamentos, automaticamente, fará parte da cultura das pessoas também.

Assim, temos muitos elementos que podem caracterizar não só os personagens, mas também, a campanha publicitária como essencialmente brasileira. Desta forma, existe sim um mito em Havaianas que envolve o "todo mundo" e que se utiliza do "jeitinho brasileiro" para a sua construção, ou seja, podemos dizer que o mito do "jeitinho brasileiro" existe em Havaianas e sua consolidação está em, "Havaianas: Todo mundo usa".

\section{REFERÊNCIAS}

BARTHES, Roland. Mitologias. Madri: Siglo Veintiuno de España Editores, 1999. BREUNIG, Jairo. Análise das ações dos revendedores varejistas nos pontos de venda em relação à estratégia de reposicionamento da marca Havaianas. Dissertação apresentada para a obtenção do grau de Mestre, pelo Programa de Pós-Graduação da Faculdade de Administração da Pontifícia Universidade Católica do Rio Grande do Sul, defendida em 2006. HOLANDA, Sérgio Buarque. Raízes do Brasil. São Paulo: Companhia da Letras, 1995.

PETERMANN, Juliana. Construindo o Mito: A Seleção Brasileira de Futebol em Época. In: XXX INTERCOM, 2007, Santos.

PERUZZOLO, C.A. A Comunicação como encontro. Bauru: Edusc, 2006.

. Elementos de semiótica da comunicação: quando aprender é fazer. Bauru: Edusc, 2004.

SERRALVO, Franscico Antônio (et al). A importância do reposicionamento de marcas no contexto competitivo: 0 caso das sandálias havaianas. In: XXX EnAnpad, 30., 2006, Salvador.

http://www.havaianas.com.br, acessado em 10 de setembro de 2009, às gh e 43 min., 17 de setembro de 2009, às $13 \mathrm{~h} 15$ min., em 29 de setembro de 2009 às $10 \mathrm{~h} 45$ min., em 03 de outubro de 2009, às $20 \mathrm{~h} 49 \mathrm{~min}$. , em 07 de outubro de 2009, às 19h 31min. http://www.culturaesociedade.org/pdf/DAMATTAJeitinho.pdf, acessado em 07 de dezembro 11h 59min (DAMATTA 2009 a).

http://www.chmkt.com.br/2009/11/entendendo-nosso-jeito-brasileiro-dee_24.html, acessado em 27 de novembro de 2009, às 12h 13min (DAMATTA 2009 b). 


\section{Carline Ternus}

Bacharel em Comunicação Social - Publicidade e Propaganda pela UFSM. Mestranda em Comunicação pelo Programa de Pós-Graduação em Ciências da Comunicação da UFSM.

\section{Juliana Petermann}

Possui graduação em Comunicação Social - Publicidade e Propaganda pela Universidade Federal de Santa Maria (2003), mestrado em Linguística Aplicada pela Universidade Federal de Santa Maria (2006), doutorado em Ciências da Comunicação pela Universidade do Vale do Rio dos Sinos (UNISINOS). Atualmente é professora Adjunta do Curso de Publicidade e Propaganda da Universidade Federal de Santa Maria. Atua principalmente nos seguintes temas: criação publicitária, marcas e seus discursos, estratégias de significação, análise do discurso verbal e não-verbal, gêneros do discurso. 